\title{
PULMONARY VENTILATION AND DIFFUSION IN THE HUMAN NEWBORN INFANT ${ }^{1}$
}

\author{
By MILDRED T. STAHLMAN with THE TEChNical ASSistance of N. JEAN MEECE \\ (From the Laboratories of Clinical Physiology, and the Departments of Physiology and Pedi- \\ atrics, Vanderbilt University, School of Medicine, Nashville, Tenn.)
}

(Submitted for publication July 5, 1956; accepted February 21, 1957)

Respiratory failure is the most common cause of morbidity and mortality in the first few days of life, particularly in the premature infant. However, the pathologic physiology of both internal and external respiration in this age group is poorly understood.

The primary obstacle to the definition of normal and altered respiratory physiology in the newborn has been the lack of practical methods for studying ventilation, diffusion and perfusion of the lungs in the very young infant. Techniques for such studies in coöperative adults are, with certain accepted limitations, well established as adequate means of quantitative measurement. Because of the marked differences in the size of the subjects, the volumes of gases to be measured, and the problems of resistance to expiration and dead space which arise when such equipment is used in small infants, these techniques have not previously been applied to the study of infants. Indirect methods, using a body plethysmograph (1-9), have allowed the estimation of some of the elements of ventilation, but cannot be applied to measurements of diffusion or distribution of inspired air.

The purpose of this paper is to describe equipment and techniques designed to allow direct quantitative measurement of ventilation and diffusion in newborn infants. Results of studies obtained by these techniques in a series of normal newborn infants are compared with similar measurements made by accepted techniques in older children and adults.

\section{METHODS}

The problems of measuring resting pulmonary ventilation in any age group depend upon the ability to measure the amount of gas respired in a one-way system with a simultaneous recording of respiratory frequency. The estimation of the diffusing properties of the pulmonary alveolar-capillary membrane has been approached by attempting to measure the diffusion capacity for a given gas.

1 This study was supported by a grant from the U. S. Public Health Service (H-1833).
The diffusion capacity for a gas is defined as that quantity of a gas transferred each minute for each millimeter of mercury difference in partial pressure of that gas across the alveolar-capillary membrane (10). Because of the technical difficulties of applying to infants methods in current use for measuring the diffusion capacity of oxygen, and the many assumptions which have to be made before it can be considered a valid measurement $(11,12)$, the steady-state carbon monoxide method of Filley was chosen as a measure of the diffusion properties of the lung (13). Since carbon monoxide, when breathed in low concentrations ( 0.1 to 0.2 per cent), combines so readily with hemoglobin, the mean effective pulmonary capillary partial pressure of carbon monoxide can be kept essentially zero and may be ignored as a measurement in this method $(14,15)$. The method requires, therefore, only a knowledge of carbon monoxide uptake and alveolar partial pressure of carbon monoxide.

Because of the necessity of keeping the apparatus dead space and resistance to expiration at a minimum in the measurement of carbon monoxide diffusion capacity and pulmonary ventilation in newborns, a double DonaldChristie box arrangement was chosen with a $500-\mathrm{ml}$. counter-balanced spirometer interposed between the boxes $(16,17)$. A small tightly-fitting contour mask of lucite, molded to fit the death mask of a premature baby, with

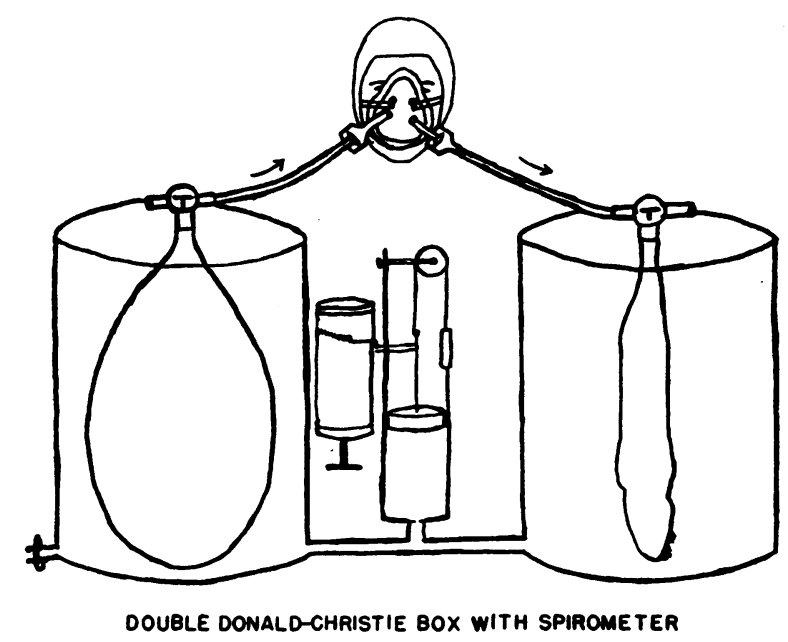

Fig. 1. Double Donald-Christie Boxes With a Small Counter-Balanced Spirometer Interposed BeTWEEN THE BOXES 
TABLE I

Data used in calculating the diffusion capacity in infants

\begin{tabular}{|c|c|c|c|c|c|c|c|c|c|}
\hline Number & Sex & $\begin{array}{l}\text { Age } \\
(h r .)\end{array}$ & $\begin{array}{l}\text { Wt. } \\
(l b .)\end{array}$ & $\begin{array}{l}\text { CO uptake } \\
(\text { ml./min.) }\end{array}$ & $\underset{\text { (art.) }}{\text { pH }}$ & $\begin{array}{c}\mathrm{CO}_{2} \text { content } \\
(m M / L . \text { plasma })\end{array}$ & $\underset{(\mathrm{mm} . \mathrm{Hg})}{\mathrm{P}_{\mathbf{g}} \mathrm{CO}_{2}}$ & $\underset{(\mathrm{mm} . \mathrm{Hg})}{\mathrm{P}_{\mathbf{A}} \mathrm{CO}}$ & $\underset{(m l . / m i n . / m m . ~ H z)}{D \infty o}$ \\
\hline $\begin{array}{l}240177 \\
240316 \\
240316 \\
240408 \\
230465 \\
240696 \\
240960 \\
241058 \\
241221 \\
241259 \\
241356 \\
241362 \\
241469 \\
241614 \\
241681 \\
241758 \\
241877 \\
242026 \\
242068 \\
242510 \\
242570 \\
242574 \\
242676 \\
242811 \\
242861 \\
242971 \\
243519 \\
243651 \\
243771 \\
243933 \\
244135 \\
244194 \\
244570 \\
244657 \\
244779 \\
244923 \\
245086 \\
247612 \\
247533 \\
247696 \\
247909 \\
248502 \\
221824 \\
248729\end{array}$ & $\begin{array}{l}\mathbf{F} \\
\mathbf{M} \\
\mathbf{M} \\
\mathbf{M} \\
\mathbf{M} \\
\mathbf{F} \\
\mathbf{F} \\
\mathbf{F} \\
\mathbf{M} \\
\mathbf{M} \\
\mathbf{F} \\
\mathbf{F} \\
\mathbf{F} \\
\mathbf{M} \\
\mathbf{M} \\
\mathbf{M} \\
\mathbf{F} \\
\mathbf{F} \\
\mathbf{F} \\
\mathbf{M} \\
\mathbf{M} \\
\mathbf{F} \\
\mathbf{F} \\
\mathbf{M} \\
\mathbf{M} \\
\mathbf{F} \\
\mathbf{M} \\
\mathbf{F} \\
\mathbf{F} \\
\mathbf{M} \\
\mathbf{M} \\
\mathbf{F} \\
\mathbf{M} \\
\mathbf{M} \\
\mathbf{M} \\
\mathbf{M} \\
\mathbf{M} \\
\mathbf{M} \\
\mathbf{M}\end{array}$ & $\begin{array}{l}81 \\
29 \\
72 \\
24 \\
50 \\
12 \\
48 \\
54 \\
75 \\
30 \\
30 \\
96 \\
52 \\
30 \\
29 \\
81 \\
80 \\
34 \\
40 \\
58 \\
40 \\
53 \\
64 \\
22 \\
30 \\
48 \\
63 \\
9 \\
53 \\
64 \\
20 \\
32 \\
13 \\
23 \\
36 \\
56 \\
13 \\
30 \\
78 \\
37 \\
20 \\
31 \\
30 \\
80\end{array}$ & 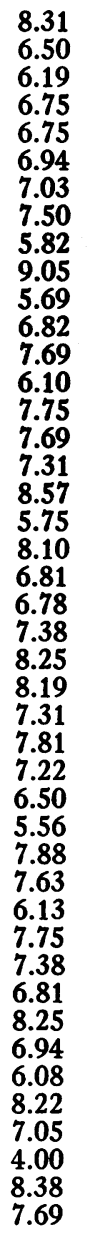 & $\begin{array}{l}.334 \\
.270 \\
.230 \\
.207 \\
.347 \\
.276 \\
.234 \\
.240 \\
.143 \\
.196 \\
.166 \\
.261 \\
.277 \\
.189 \\
.218 \\
.260 \\
.244 \\
.227 \\
.330 \\
.322 \\
.253 \\
.274 \\
.316 \\
.190 \\
.282 \\
.237 \\
.172 \\
.211 \\
.252 \\
.188 \\
.266 \\
.250 \\
.194 \\
.250 \\
.215 \\
.176 \\
.155 \\
.156 \\
.184 \\
.310 \\
.139 \\
.172\end{array}$ & $\begin{array}{l}7.43 \\
7.42 \\
7.47 \\
7.39 \\
7.46 \\
7.50 \\
7.44 \\
7.41 \\
7.48 \\
7.42 \\
7.43 \\
7.46 \\
7.39 \\
7.43 \\
7.41 \\
7.47 \\
7.46 \\
7.45 \\
7.45 \\
7.43 \\
7.40 \\
7.43 \\
7.38 \\
7.45 \\
7.42 \\
7.42 \\
7.44 \\
7.39 \\
7.44 \\
7.41 \\
7.44 \\
7.43 \\
7.39 \\
7.44 \\
7.41 \\
7.46 \\
7.41 \\
7.42 \\
7.42 \\
7.44 \\
7.45 \\
7.43 \\
7.50\end{array}$ & $\begin{array}{l}23.18 \\
16.32 \\
16.03 \\
15.55 \\
22.26 \\
20.60 \\
17.48 \\
23.10 \\
22.48 \\
23.30 \\
19.84 \\
20.91 \\
19.26 \\
21.91 \\
24.10 \\
19.94 \\
23.20 \\
23.04 \\
27.98 \\
23.32 \\
23.03 \\
32.48 \\
23.08 \\
22.39 \\
23.61 \\
26.42 \\
21.18 \\
20.70 \\
21.64 \\
21.35 \\
23.10 \\
22.87 \\
20.87 \\
21.78 \\
21.60 \\
21.52 \\
21.53 \\
25.13 \\
20.16 \\
20.40 \\
20.80 \\
19.95\end{array}$ & $\begin{array}{l}33.0 \\
23.8 \\
20.9 \\
20.7 \\
27.1 \\
28.7 \\
26.0 \\
29.5 \\
32.7 \\
33.2 \\
26.6 \\
33.2 \\
27.4 \\
32.6 \\
31.8 \\
26.6 \\
31.6 \\
31.4 \\
39.8 \\
35.4 \\
32.8 \\
29.7 \\
31.4 \\
32.6 \\
34.4 \\
36.8 \\
32.9 \\
28.8 \\
32.2 \\
29.7 \\
32.8 \\
35.5 \\
29.0 \\
32.4 \\
28.8 \\
32.0 \\
31.3 \\
36.6 \\
28.1 \\
29.1 \\
29.6 \\
24.3\end{array}$ & $\begin{array}{l}.146 \\
.086 \\
.234 \\
.159 \\
.138 \\
.231 \\
.218 \\
.222 \\
.223 \\
.129 \\
.056 \\
.047 \\
.234 \\
.130 \\
.246 \\
.201 \\
.168 \\
.088 \\
.130 \\
.184 \\
.235 \\
.214 \\
.097 \\
.180 \\
.141 \\
.218 \\
.101 \\
.110 \\
.138 \\
.065 \\
.072 \\
.105 \\
.111\end{array}$ & $\begin{array}{l}1.89 \\
3.10 \\
1.03 \\
1.24 \\
1.20 \\
1.14 \\
0.87 \\
0.98 \\
1.09 \\
1.76 \\
\\
1.08 \\
2.11 \\
1.28 \\
0.94 \\
1.68 \\
2.69 \\
1.62 \\
1.37 \\
0.80 \\
1.24 \\
2.58 \\
1.08 \\
1.77 \\
0.99 \\
1.41 \\
1.68 \\
2.25 \\
2.14 \\
1.15 \\
2.72 \\
1.55\end{array}$ \\
\hline
\end{tabular}

an inflatable soft rubber cuff, was interposed between the neoprene bags with connecting rubber tubing, and small, low resistance " $\mathrm{J}$ " valves were placed on the inspired and expired sides of the mask to insure one-way gas flow to and from the bags. As the baby took in a breath from the inspiratory bag, the pressure in the boxes, which were widely connected, was lowered and the spirometer fell. With expiration into the second bag, the pressure in the box system was equalized and the spirometer rose. Any difference in inspired and expired volume was compensated for by the slope of the respiratory curve which was therefore a reflection of respiratory quotient. Respiratory frequency could be read from the curve, inspired and expired gas concentrations analyzed separately without dilution, and the expired volume measured by emptying the expired bag into a nine-liter calibrated Collins spirometer. Figure 1 shows a diagram of the system. The in- spired and expired carbon monoxide concentration were analyzed with a Liston-Becker Infra-Red Carbon Monoxide Meter set at full scale deflection with 0.1 per cent carbon monoxide, with an accuracy of \pm 2 per cent of full scale. The expired and inspired oxygen, carbon dioxide, and nitrogen concentrations were measured with the Scholander Gas Analyzer, double determinations being required to check within 0.04 per cent. With this system, carbon monoxide uptake, minute ventilation, alveolar ventilation, oxygen uptake, and carbon dioxide output, frequency of respiration and tidal volume were obtained.

Arterial blood was collected anerobically in greased sterile 2-ml. syringes, the dead space of which had been filled with sterile heparin solution. The syringes were capped with mercury-seal caps and iced immediately. Arterial blood $\mathrm{pH}$ was done in duplicate on the Cambridge $\mathrm{pH}$ Meter at room temperature and corrected to 
TABLE II

Data used in ventilatory calculations in infants

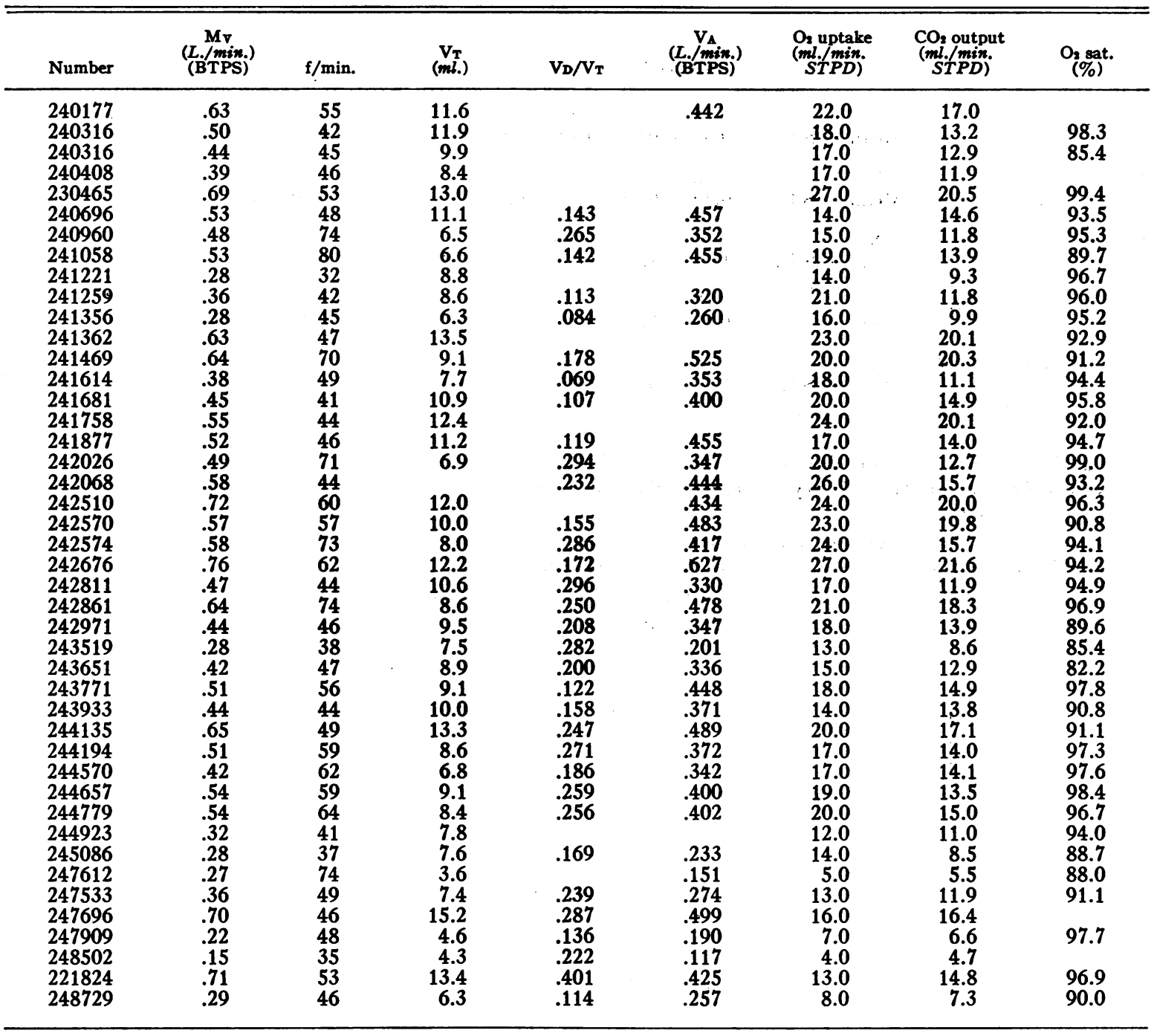

$37^{\circ} \mathrm{C}$. by subtracting $0.01 \mathrm{pH}$ units for each degree below $37^{\circ} \mathrm{C}$. Oxygen capacity, oxygen and carbon dioxide contents were run in duplicate on $0.2-\mathrm{ml}$. samples of whole blood on the Van Slyke Manometric Gas Apparatus. The Van Slyke and Sendroy line chart was used to calculate the plasma carbon dioxide content from that of whole blood (18).

All babies were from fifteen to forty-five minutes postprandial and most were sleepy or frankly asleep. A generous injection of Novocain was administered into the right femoral triangle and this usually elicited one or two loud cries which rapidly subsided if the baby was soothed. A 20-minute wait followed during which time the baby was held on the operator's lap and rocked; then a femoral arterial puncture was attempted and, whenever possible, three 2-ml. syringes of blood obtained. If sig- nificant crying occurred the procedure was abandoned. As soon as the blood was obtained, the baby was wrapped in a sheet restraint, placed on the operator's lap and the mask placed gently on the face. If no crying occurred (usually the baby went promptly back to sleep if handled gently), the baby was allowed a two-minute equilibration period breathing 0.1 per cent carbon monoxide in air in order to wash the lungs with carbon monoxide and to insure that the carbon monoxide uptake to carbon dioxide output ratio was a constant one (13). The kymograph was then started and the 3-way valves on the two bags turned so as to allow the baby to breathe out of the first bag and into the second one. The first bag had been rinsed and filled with 0.1 per cent carbon monoxide in air, and the second one rinsed with room air and emptied to its dead space which had been previously meas- 
TABLE III

The relationship of ventilatory and diffusion data to body weight in infants

\begin{tabular}{|c|c|c|c|c|c|c|c|}
\hline & \multirow{2}{*}{. } & \multicolumn{4}{|c|}{ Body weight (pounds) } & \multirow{2}{*}{$\begin{array}{l}\text { Correlation } \\
\text { Coefficient }\end{array}$} & \multirow{2}{*}{$\underset{\text { value }}{P}$} \\
\hline & & 4.0 to 6.5 & 6.5 to 8.0 & 8.0 to 8.1 & Total & & \\
\hline $\mathbf{M}_{\mathbf{v}}$, L./min. & $\stackrel{N}{\text { Mean }} \pm$ S.E. & $0.84=0.04$ & $\begin{array}{l}26 \\
0.49\end{array} 0.03$ & $\stackrel{9}{0.58} \pm 0.06$ & $0.49 \pm 0.02$ & +0.46 & $<0.01$ \\
\hline $\mathrm{V}_{\mathbf{A}}, L . / \min$ & $\stackrel{\mathrm{N}}{\text { Mean }} \pm$ S.E. & $0 . \stackrel{6}{9}^{6} \pm 0.04$ & $\stackrel{18}{0.41} \pm 0.02$ & $\stackrel{7}{7} \pm 0.05$ & $\begin{array}{l}31 \\
0.39\end{array} \pm 0.02$ & +0.41 & $<0.05$ \\
\hline $\mathrm{O}_{2}$ uptake, ml./min. & $\stackrel{\mathrm{N}}{\text { Mean }} \pm$ S.E. & 15.9 士 1.9 & $\begin{array}{r}26 \\
17.7\end{array}$ 土1.1 & 20.9 & $17.8 \pm 0.8$ & +0.31 & $<0.05$ \\
\hline CO uptake, ml./min. & $\stackrel{\mathrm{N}}{\text { Mean }} \pm$ S.E. & $\stackrel{9}{0.19} \pm 0.02$ & $0.24 \pm 0.01$ & $\stackrel{9}{0.27} \pm 0.02$ & $0.23 \pm 0.01$ & +0.39 & $<0.01$ \\
\hline Dco, ml./min./mm. $H g$ & $\stackrel{\mathrm{N}}{\text { Mean }} \pm$ S.E. & $\frac{6}{1.13} \pm 0.13$ & $\begin{array}{l}18 \\
1.65\end{array} \pm 0.15$ & $\frac{7}{1.70} \pm 0.20$ & $\begin{array}{l}31 \\
1.56\end{array}$ =0.11 & +0.24 & $<0.25$ \\
\hline
\end{tabular}

ured as $20 \mathrm{ml}$. The baby was then allowed to breathe in the system for four minutes. If crying occurred the collection was discontinued.

The diffusion and ventilation measurements on the older children and adults were made by the method of Filley, MacIntosh, and Wright, using a one-way system of gas collection, and the same inspired mixture of carbon monoxide as that used for the babies (13). An indwelling arterial needle had been placed previously in a brachial or femoral artery, and the collection of blood was made simultaneously with the collection of expired gas.

Posterior-anterior and lateral X-ray films of the chest were also made on most of the subjects, both the

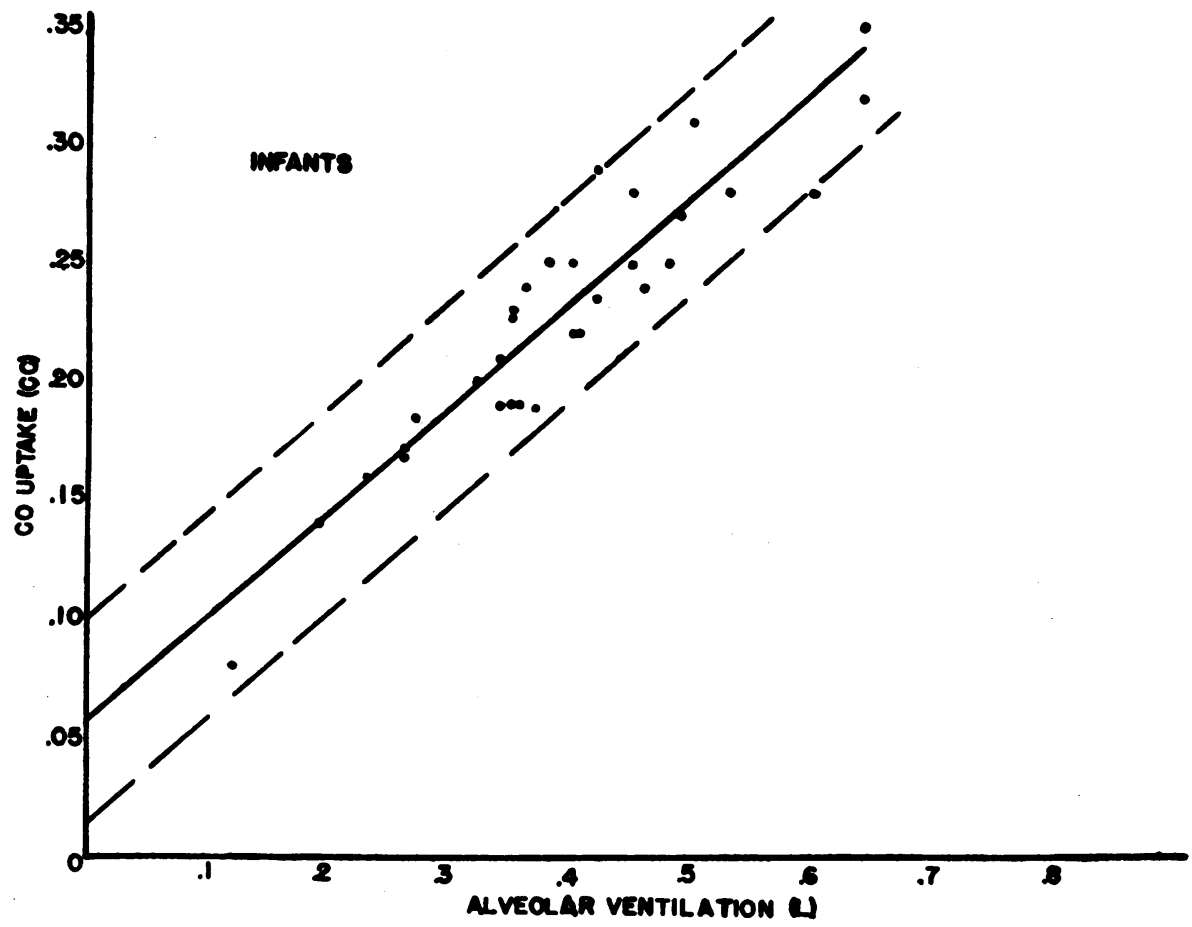

Fig. 2. The Correination of CO Uptake in ML. per Minute With Alveolar Ventilation in Ltters per Minute in 31 Normal Newborn Infants

The solid line represents the regression line for the data and the broken lines represent two standard deviations around the regression line. 


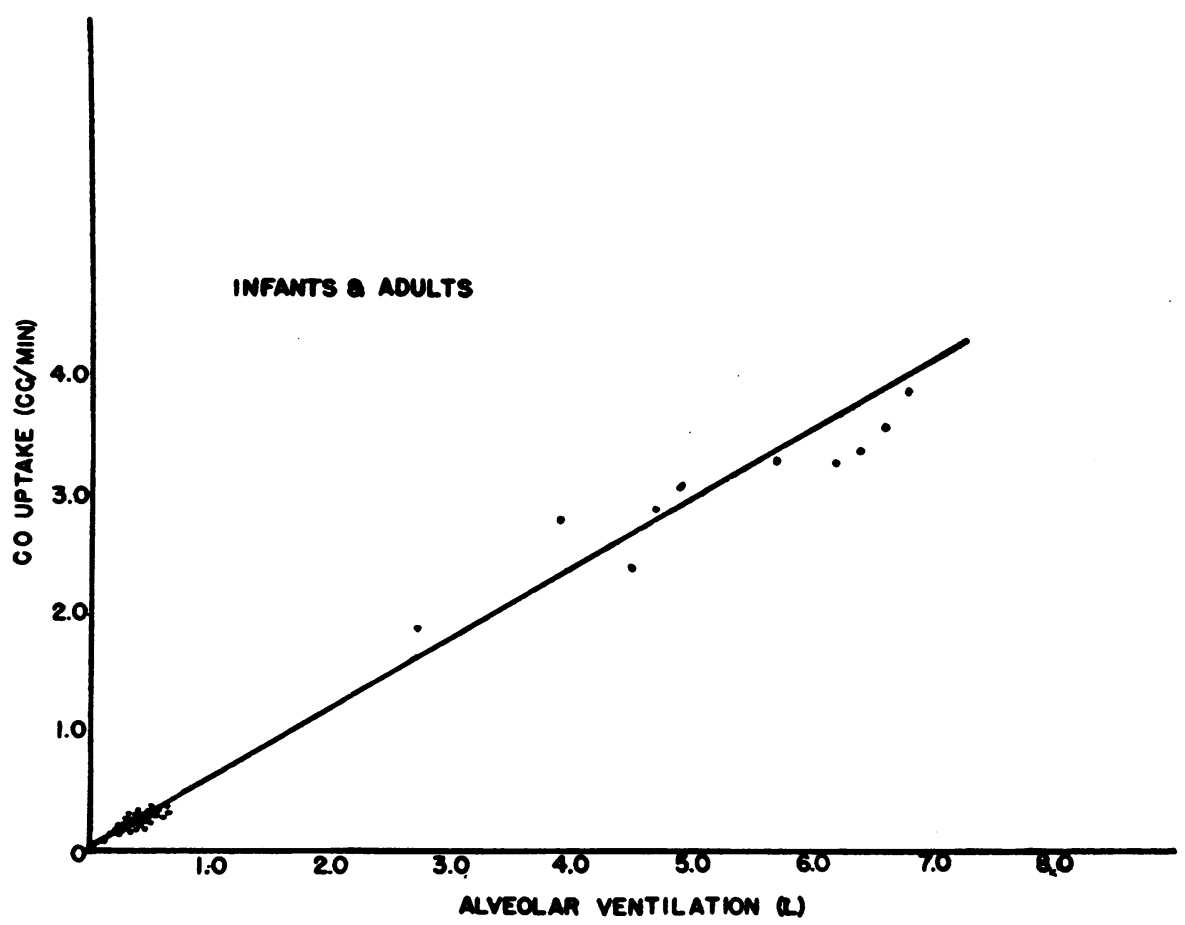

Fig. 3. The Correlation of CO Uptake in ML. per Minute With Alveolar Ventilation in Liters per Minute in 31 Noracal Newborn Infants as Compared With 12 Normal Older Chindren and Adults

The solid line represents the regression line for the combined data.

babies and adults, and all were interpreted by the radiologists as normal. The $\mathrm{X}$-rays of the babies were made within four hours after their diffusion studies.

\section{Subjects}

Ventilation and diffusion studies have been completed in 31 normal, newborn infants ranging in age from 9 to 96 hours, with a mean age of 38 hours. They varied in weight from 4 to 9 pounds, with a mean weight of 7.16 pounds. The babies were selected at random from a small staff newborn service. There were $18 \mathrm{males}$ and 13 females. Ventilatory studies, carbon monoxide uptake and blood gases were measured on an additional number of babies on whom, for various technical reasons, diffusion measurements could not be completed.

For purposes of comparison, the same ventilation and diffusion studies were carried out on 12 normal older children and adults of varying body size.

\section{Calculations}

All definitions and symbols are those designated by the Committee on Standardization of definitions and symbols in respiratory physiology of the American Physiological Society (10). The minute ventilation, $M_{\mathbf{v}}$, and alveolar ventilation, $\dot{V}_{\mathbf{A}}$, were expressed in liters per minute at BTPS. The CO uptake in $\mathrm{ml}$. of $\mathrm{CO}$ per minute was calculated as $\dot{V}_{\mathrm{E}}\left(F_{\mathrm{Io0}}\left(\frac{F_{\mathrm{EN}_{2}}}{F_{\mathrm{IN}_{2}}}\right)-F_{\mathrm{Ro0}}\right)$, where $\dot{V}_{\mathrm{E}}$ is the total gas volume STPD expired per minute, $F_{I}$ and $F_{E}$ are gas concentrations in inspired and expired volumes, and the subscripts refer to the gases in question. The alveolar carbon monoxide tension was calculated by using a form of the Bohr relation for the alveolar equation and assuming that the alveolar $\mathrm{CO}_{2}$ tension, $\mathrm{P}_{4} \mathrm{CO}_{2}$, is equal to the arterial $\mathrm{CO}_{2}$ tension, $\mathrm{P}_{2} \mathrm{CO}_{2}$. The equation used was (13):

$$
P_{A \infty 0}=\frac{F_{E \infty 0}-r F_{100}}{1-r}\left(P_{B}-47\right)
$$

where

$$
\mathbf{r}=\frac{\mathrm{V}_{\mathrm{D}}}{\mathrm{V}_{\mathrm{T}}}=\frac{\mathrm{P}_{\mathrm{a}} \mathrm{CO}_{2}-\mathrm{P}_{\mathrm{E}} \mathrm{CO}_{2}}{\mathrm{P}_{\mathrm{a}} \mathrm{CO}_{2}}
$$

\section{RESULTS}

It was felt that the "steady-state" was achieved in 31 of these babies, covering the time between the taking of femoral arterial blood and the collection of expired gas. In an additional 8 infants, although all data necessary for the calculation of $D_{c o}$ were obtained, the values for dead space to tidal volume ratios were found to be so abnormally high or low that the diffusion capacity 


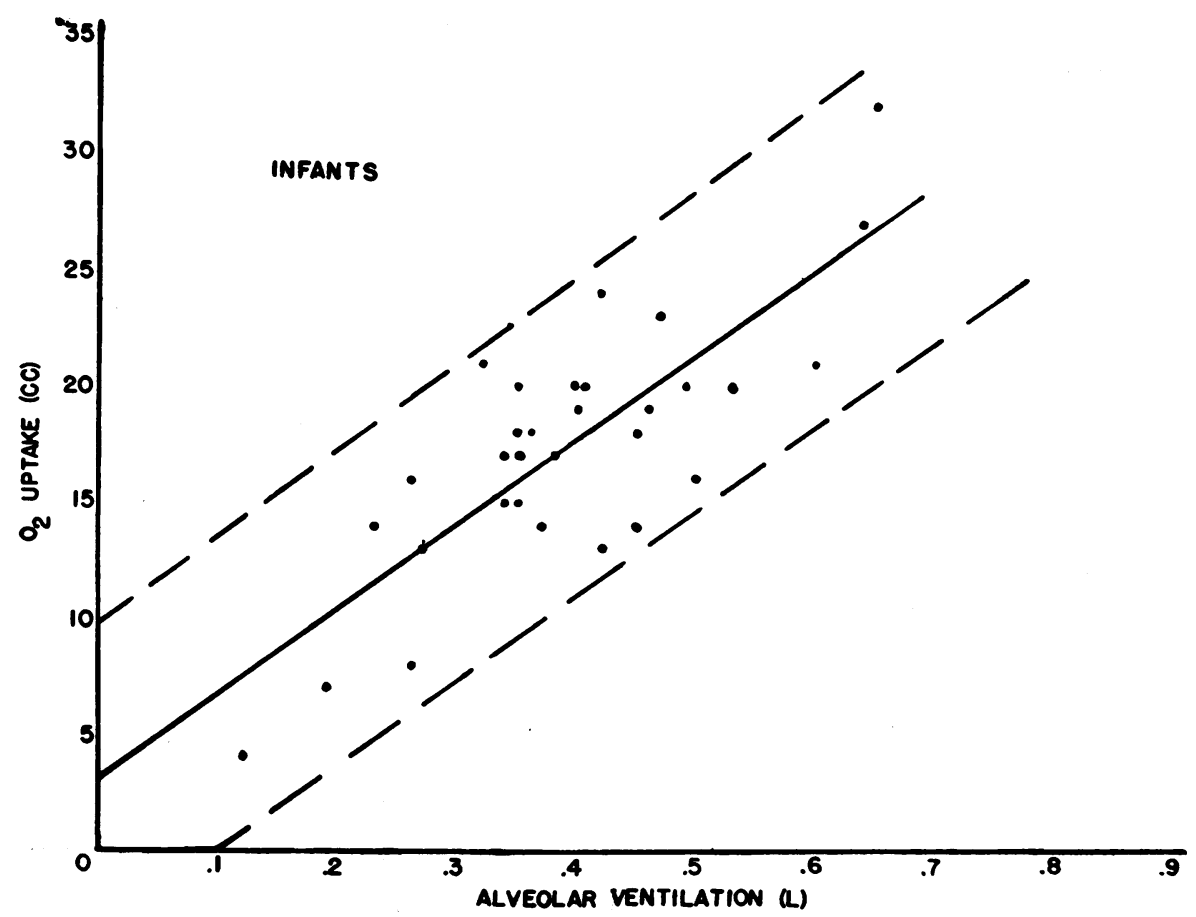

Fig. 4. The Corrriation of Oxygrn Uptake in Ml. per Minute With Alveolar Ventilation in Liters per Minute in 31 Normal Newborn Infants

The solid line represents the regression line for the data and the broken line represents two standard deviations around the regression line.

could not be calculated. It must be presumed that these babies were not in a steady state throughout the collection of blood and gas samples. Table I shows both direct determinations and data used in calculating the diffusion capacity on all infants. Table II shows both direct and calculated ventilatory data on all subjects.

The relationship of values obtained on the infants to body weight is shown in Table III.

The correlations of carbon monoxide uptake and oxygen uptake with alveolar ventilation in infants, and in infants combined with adults are shown in Figures 2, 3, 4, and 5. The correlation between oxygen uptake and carbon monoxide uptake in infants, and in infants combined with adults is shown in Figures 6 and 7.

\section{DISCUSSION}

The first question which will be reasonably brought up by pediatricians concerning such a study on newborn infants is the question of the safety of using carbon monoxide as a diffusion gas to be measured. If one takes the mean carbon monoxide uptake values for these babies of 0.23 $\mathrm{ml}$. per min. with a mean weight of 7.16 pounds, and a mean total hemoglobin of 35 grams for babies of the same weight (19), and calculates the amount of hemoglobin combined with carbon monoxide in six minutes of breathing carbon monoxide at this low concentration, it amounts to approximately $1 / 35$ of the baby's total hemoglobin. Even in conditions of respiratory distress, when all the hemoglobin may be needed for oxyhemoglobin combination, this would seem to be a negligible amount and would be the equivalent to the temporary removal of about $7 \mathrm{ml}$. of blood from a newborn infant.

The body plethysmograph which has been used previously in ventilatory studies in infants offers numerous disadvantages in studies requiring accurate measurements of gas uptake. In addition, the sensitivity of such a system is such as to dampen out the very small tidal volumes which occur with the rapid phase of small infants' arrhythmical breathing. The requirements of a system utilizing direct measurements of ventila- 


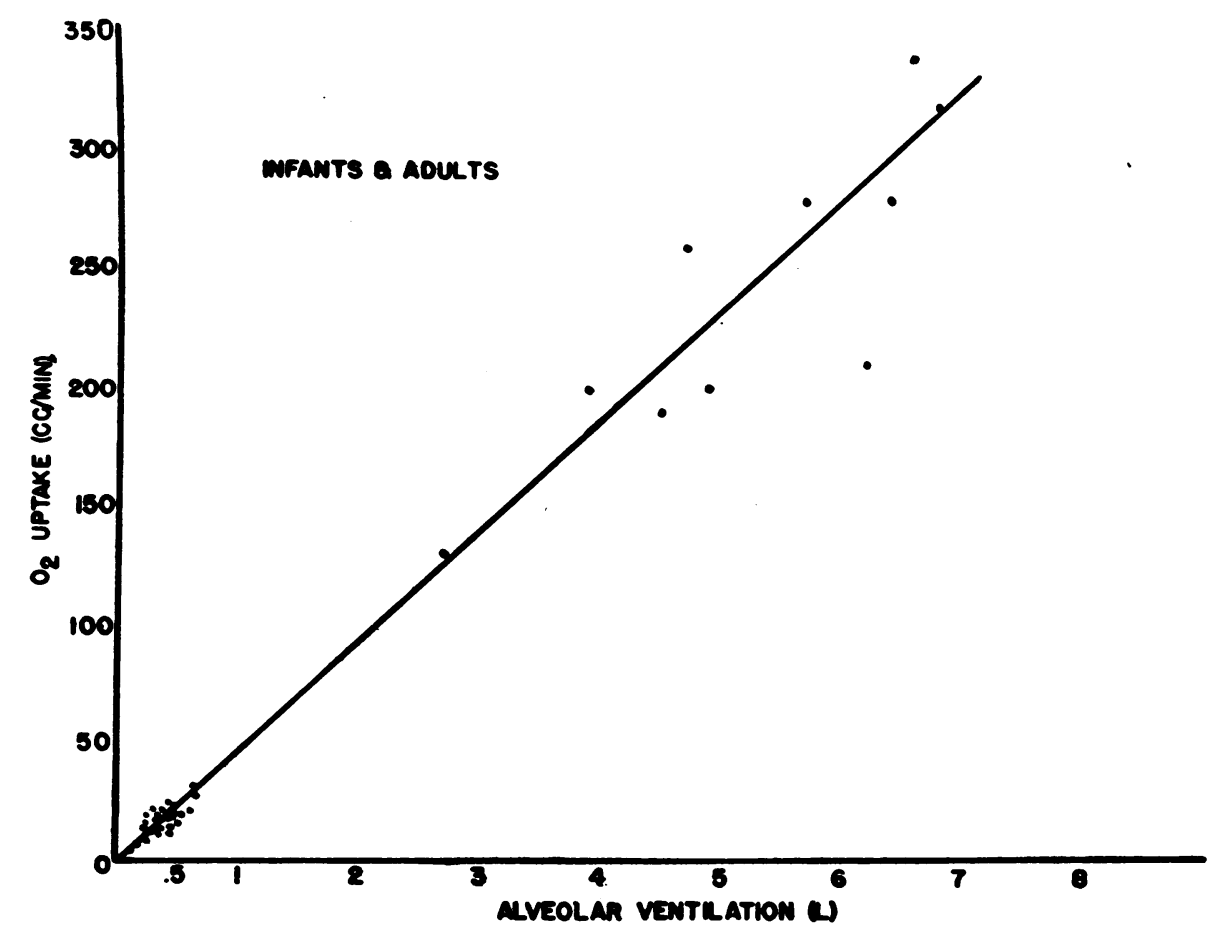

Fig. 5. The Correlation of Oxygen Uptake in Ml. per Minute and Alveolar Ventilation in Liters per Minute in 31 Normal Newborns as Compared With 12 Normal Older Chitdren and Adults

The solid line represents the regression line for the combined data.

tion and gas uptake in a one-way circuit in small infants are primarily those of negligible resistance and dead space. Resistance to expiration was kept low by using the lowest resistance type of one-way valves, small " $J$ " valves, the diameter of which was chosen as $5 \mathrm{~mm}$. The tracheas of six infants dying between birth and six months of age were measured in their smallest diameter just above the coryna at autopsy and none was found to have dimensions greater than 4 by $6 \mathrm{~mm}$. in their AP and lateral measurements. The use of a double "bag-in-box" system with a weight-compensated, low resistance spirometer interposed between the boxes contributed toward keeping the resistance to expiration minimal.

The anatomical dead space of the mask obviously varied slightly with how tightly the mask fitted the anatomical outlines of each baby's face. That the physiological dead space of the mask was quite small is demonstrated by the low physiological dead space measurements which were obtained on most babies, all of which could be accounted for by the upper respiratory passages.
The ventilatory measurements of minute ventilation and alveolar ventilation obtained in these infants agree favorably with those measurements found in the literature made indirectly with the body plethysmograph (1-9). Respiratory frequency in this series of babies is higher than in most series counted by other methods, and therefore the average tidal volumes are somewhat less than those in the literature. However, the dead space-tidal volume ratios are comparable to other series of normal newborns and therefore the physiological dead space measurements are less than those quoted. All these differences can be accounted for by the higher respiratory frequency recorded by this system. It should be noted, however, that this is a skewed distribution. There are several possible explanations for such increases in frequency. The infant's normal respiratory pattern might be disturbed by the mask and valve system in such a way as to increase the rate of breathing. Since minute ventilation, alveolar ventilation, carbon dioxide output, oxygen uptake and their ratios were undisturbed by the system, it is 


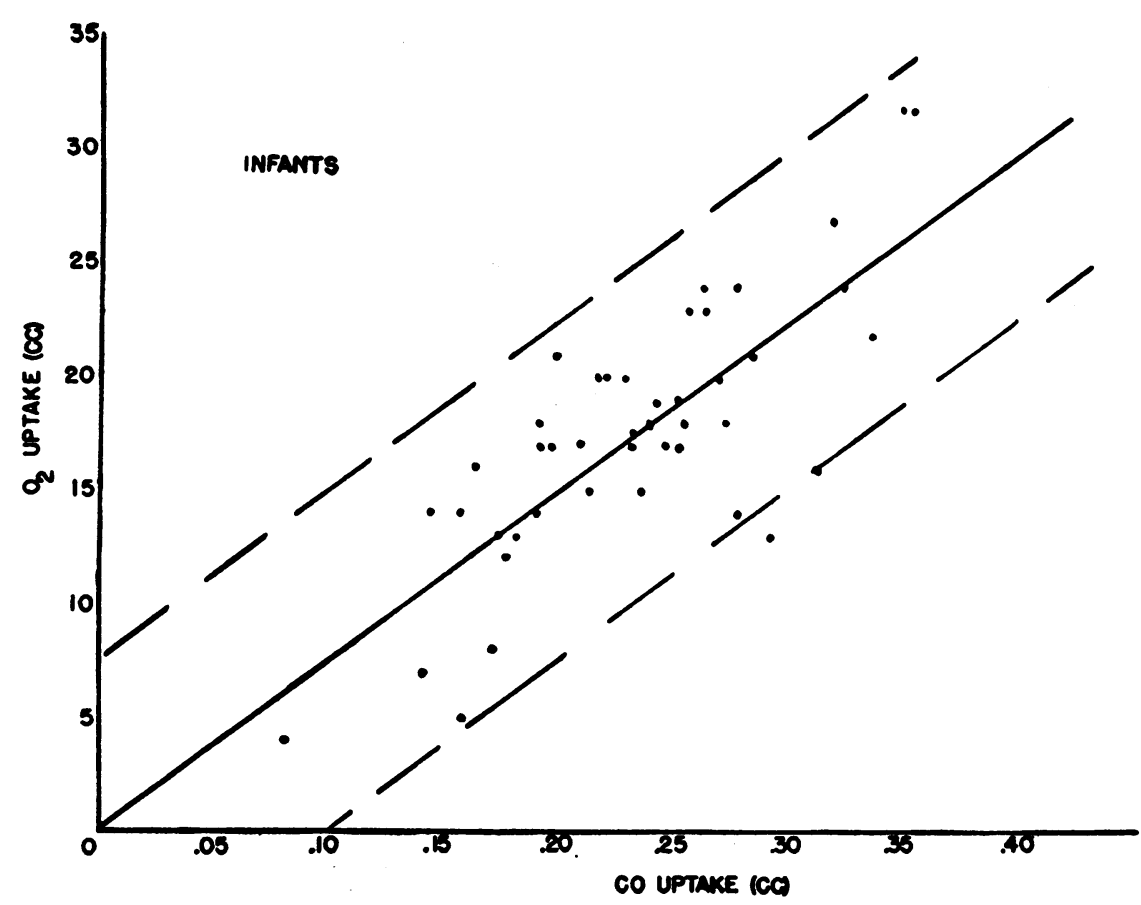

Fig. 6. The Correration of Oxygen Uptake in ML. Per Minute With CO Uptake In ML. PER Minute in 31 Norual Newborn Infants

The solid line represents the regression line for the data and the broken line represents two standard deviations around the regression line.

unlikely that this increased rate was the result of any significant change in the overall pattern of the infants' total respiratory physiology. Other possible factors to account for this difference in rate are the sensitivity of this system to small fluctuations in respiratory pattern as compared with that of the body plethysmograph, and the possible difference in ambient temperature between laboratories. The usual temperature of the room in which these measurements were made was between $85^{\circ}$ and $90^{\circ} \mathrm{F}$. In addition, the baby was swaddled in a sheet or light blanket restraint. Additional evidence that the increased rate was not due to a disturbance of the normal resting pulmonary physiology and metabolism is that the ventilatory values, when plotted against the gas uptake values, are well correlated in both infants and adults despite the fact that they were measured by different techniques as far as apparatus dead space and resistance are concerned.

Another factor in judging the validity of these data is the assumption of the steady-state from the time of doing the femoral arterial puncture through the end of the gas collection. If any significant crying occurred at any time the procedure was abandoned from that point. To test the assumption that the arterial partial pressure of carbon dioxide, as determined from blood taken from ten to fifteen minutes before the gas collection, represented the alveolar partial pressure of carbon dioxide during the time of gas collection, the Henderson continuous alveolar sampler was modified for infants (20). A series of 18 consecutive determinations was made comparing arterial partial pressure of carbon dioxide, as calculated from arterial whole blood carbon dioxide content and arterial $\mathrm{pH}$, and the alveolar partial pressure of carbon dioxide obtained directly from the alveolar sample taken during the subsequent fifteen minutes. These data are shown in Table IV. Two of the differences were so large that gross error in determinations or an unsteady state must have occurred. For the 16 other pairs, the air determinations exceeded the blood determinations by $0.2 \mathrm{~mm}$. $\mathrm{Hg}$ on the average, with a standard error of $\pm 0.4 \mathrm{~mm}$. $\mathrm{Hg}$, indicating no evidence of 


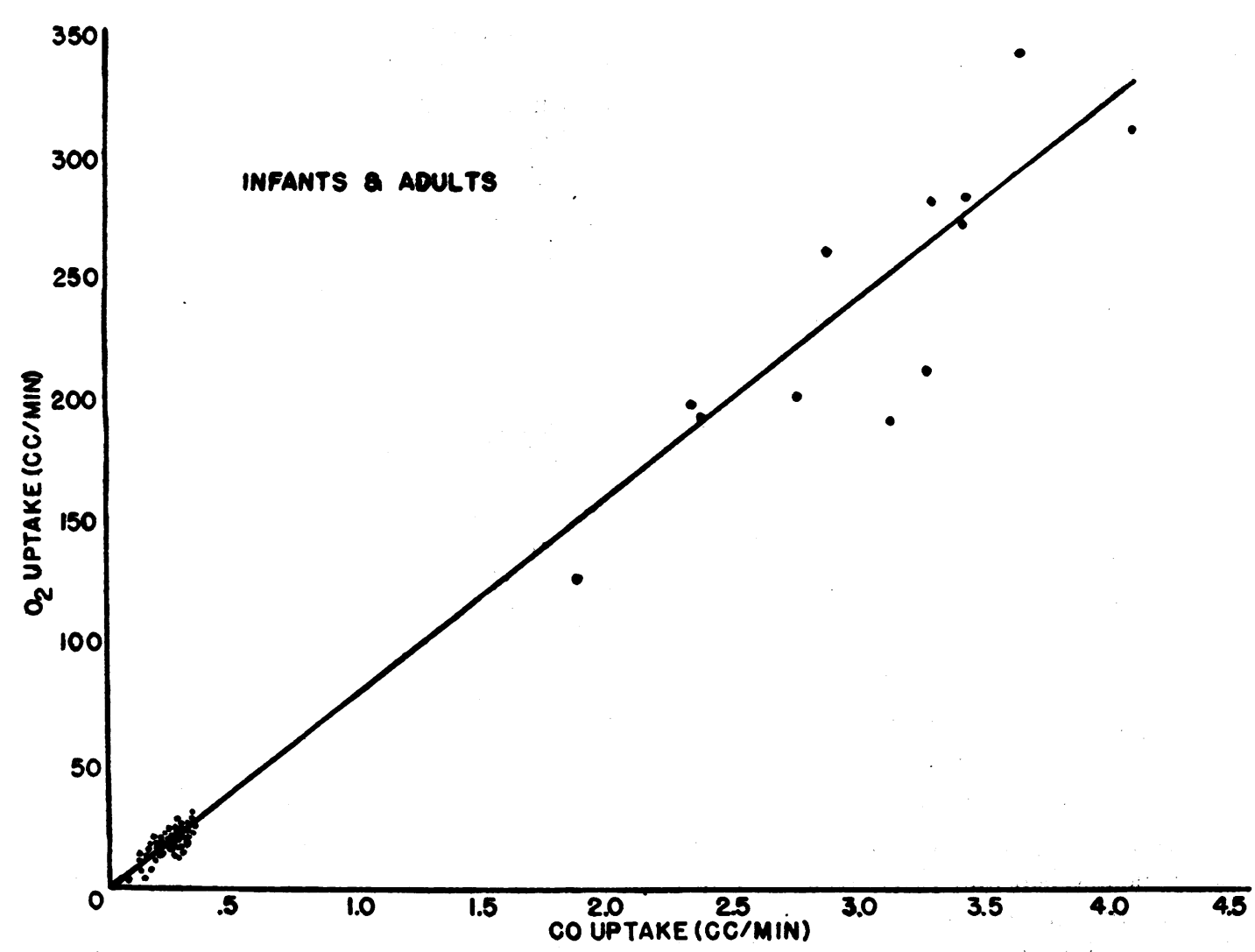

Fig. 7. The Correlation of Oxygen Uptake in Ml. per Minute With Co Uptake in Me. perr Minute in 31 Normal Newborn Infants as Compared With 12 Normal Older Children and Adults

The solid line represents the regression line for the combined data.

bias. The standard deviation for the distribution of differences of the 16 pairs was $1.5 \mathrm{~mm}$. $\mathrm{Hg}$. These data lend validity to the assumption that the steady-state was usually achieved, but also show that occasionally when this is not the case the calculated values for partial pressure of carbon dioxide might be a source of error of considerable magnitude. As has been mentioned, this was presumably true in 8 of 39 babies.

The validity of calculating the arterial partial pressure of carbon dioxide from arterial $\mathrm{pH}$ measured at room temperature and the whole blood carbon dioxide content was checked by placing six 10-ml. samples of whole blood in a 500-ml. tonometer, filling the tonometer with a known concentration of carbon dioxide (about 5 per cent), incubating it with constant rotation at $37^{\circ} \mathrm{C}$. for 45 minutes and analyzing the blood for $\mathrm{pH}$, oxygen and carbon dioxide content and oxygen capacity as usual. The arterial partial pressure of carbon dioxide was then calculated and compared with the known carbon dioxide tension with a mean difference of $1.03 \mathrm{~mm}$. $\mathrm{Hg}$ and a greatest difference of $1.63 \mathrm{~mm}$. $\mathrm{Hg}$, and it was assumed that the usual method of calculating $\mathrm{P}_{\mathrm{a}} \mathrm{CO}_{2}$ was satisfactorily accurate.

The sources of error inherent in the measurement of pulmonary gaseous diffusion using the steady-state carbon monoxide method have been discussed in detail by Filley, MacIntosh, and Wright (13).

The factors which might be expected to modify the diffusion capacity of gas, assuming that the measurements are accurate, are the total surface area of the alveolar membrane in contact with patent capillaries, the thickness of this membrane and its permeability. As yet these three properties of the membrane cannot be adequately separated. It might be expected that carbon monoxide uptake would have a positive correlation with 
TABLE IV

Comparison of arterial and alveolar carbon dioxide tensions in eighteen infants

\begin{tabular}{cc}
\hline \hline $\begin{array}{c}\mathrm{P}_{\mathrm{A}} \mathrm{CO}_{2} \\
(\mathrm{~mm} . \mathrm{Hg})\end{array}$ & $\begin{array}{c}\mathrm{P}_{\mathrm{g}} \mathrm{CO}_{2} \\
(\mathrm{~mm} . \mathrm{Hg})\end{array}$ \\
\hline 33.9 & 36.6 \\
28.5 & 28.1 \\
34.1 & 24.3 \\
33.3 & 31.3 \\
30.2 & 29.5 \\
28.5 & 26.5 \\
30.4 & 28.8 \\
24.6 & 24.8 \\
34.5 & 34.0 \\
24.6 & 26.5 \\
28.3 & 28.2 \\
32.8 & 31.8 \\
29.5 & 29.7 \\
24.8 & 31.3 \\
31.8 & 33.3 \\
29.2 & 27.6 \\
29.9 & 28.7 \\
28.9 & 31.0 \\
\hline
\end{tabular}

body size since this would be a reflection of the surface area of the alveolar membrane available for diffusion, provided the lungs were well expanded. Since oxygen uptake is a reflection of total body metabolism and since alveolar ventilation reflects the gaseous exchange between the alveoli and outside air necessary to provide adequate oxygen uptake and carbon dioxide output, it would be expected that alveolar ventilation and oxygen uptake would show positive correlations with body weight as is the case. The alveolar partial pressure of carbon monoxide, however, would not be expected to vary with body size but with the dead space to tidal volume ratio, alveolar ventilation and $D_{0 o}$ and no correlation can be shown between $\mathrm{P}_{\mathbf{A}} \mathrm{CO}$ and body weight. Since $\mathrm{D}_{\mathrm{co}}$ is a calculated ratio between $\mathrm{CO}$ uptake and $\mathrm{P}_{\mathbf{A}} \mathrm{CO}$, it is understandable that, with small differences in body size among the babies studied, the differences in $D_{c o}$ from one weight group to another are not statistically different although there is a progressive increase in $D_{c o}$ demonstrated in each increase in weight group among the infants.

It can be noted that the $\mathrm{pH}$ of arterial blood in these babies was within the normal adult range and that the arterial plasma $\mathrm{CO}_{2}$ content was considerably lower. This made the $\mathrm{P}_{\mathrm{a}} \mathrm{CO}_{2}$ in the newborn as calculated from the Henderson-Hasselbach equation lower than the normal adult level by an average of 8 to $10 \mathrm{~mm}$. $\mathrm{Hg}$.
The oxygen saturation in 15 of the 31 babies was 95 per cent or above, and was below 90 per cent in only 6 . There was no correlation between $\mathrm{D}_{\mathrm{co}}$ and oxygen saturation and the lungs of these partially saturated babies appear to be well expanded on X-ray examination, and no baby was considered to be in respiratory distress at any time. It is therefore suggested that the degree of unsaturation found in femoral arterial blood of these non-crying babies was due to persistent right-to-left fetal shunts, intra-cardiac or extracardiac (21).

The good correlation of $\mathrm{CO}$ uptake and alveolar ventilation in both infants and adults has been shown by other investigators, not only at rest but also during work and during voluntary hyperventilation (13). To check whether this spread in alveolar ventilation values in these infants was due to true differences in ventilation need, or to hyperventilation, the oxygen uptake was also plotted against alveolar ventilation. This also shows a high degree of correlation for both sets of data. The RQ's were normal in these babies, the mean being 0.80 , which tends to exclude hyperventilation as a cause for these differences in alveolar ventilation from baby to baby. Since oxygen consumption should not be affected in the same way as $\mathrm{CO}$ uptake by hyperventilation, the data for oxygen uptake and $\mathrm{CO}$ uptake were plotted against each other for both infants and adults. They correlate well, with the origins of the regression lines passing through zero. This is further evidence that hyperventilation was not an important factor in values obtained for $D_{c o}$ in these infants.

\section{SUMMARY AND CONCLUSIONS}

1. The Filley steady-state carbon monoxide method of estimating the diffusion of gases across the pulmonary alveolar-capillary membrane has been modified for use in newborn infants.

2. A method for making direct ventilation and gas uptake measurements utilizing a face mask and double Donald-Christie box with a spirometer interposed between the boxes has been designed for use in infants.

3. Diffusion and ventilation studies have been carried out in 31 normal newborn infants and in 12 normal older children and adults for comparison. 
4. Ventilation studies are described in an additional fifteen newborn infants in whom diffusion studies were not completed.

5. Carbon monoxide uptake, alveolar ventilation, minute ventilation, oxygen uptake, and the diffusion capacity for carbon monoxide are shown to increase with body weight in infants.

6. Carbon monoxide uptake and oxygen uptake are shown to correlate well with alveolar ventilation in both infants and adults and carbon monoxide uptake correlates well with oxygen uptake.

7. Although the method has inherent drawbacks as a measure of gaseous diffusion across the pulmonary alveolar-capillary membrane, it is thought that it can be applied to newborn infants in respiratory distress in an attempt to delineate the types of pathological pulmonary physiology which occur in the newborn period.

\section{ACKNOWLEDGMENT}

The author gratefully acknowledges the statistical assistance of Mr. Edwin Bridgeforth, Department of Preventive Medicine, Vanderbilt University, School of Medicine, Nashville, Tennessee.

\section{REFERENCES}

1. Deming, J., and Washburn, A. H., Respiration in infancy-I. A method of studying rates, volume, and character of respiration with preliminary report of results. Am. J. Dis. Child., 1935, 49, 108.

2. Deming, J., and Hanner, J. P., Respiration in infancy-II. A study of rate, volume, and character of respiration in healthy infants during the neonatal period. Am. J. Dis. Child., 1936, 51, 823.

3. Cross, $K$. W., The respiratory rate and ventilation in the newborn baby. J. Physiol., 1949, 109, 459.

4. Boutourline-Young, H. J., and Smith, C. A., Respiration of full term and of premature infants. Am. J. Dis. Child., 1950, 80, 753.

5. Cross, K. W., and Oppé, T. E., The respiratory rate and volume in the premature infant. J. Physiol., 1952, 116, 168.

6. Cross, K. W., Plethysmograph for studying respiration in the newborn infant. J. Physiol., Proceedings of the Physiological Society, 1949, 108, 37.
7. Cook, C. D., Cherry, R. B., O'Brien, D., Karlberg, P., and Smith, C. A., Studies of respiratory physiology in the newborn infant. I. Observations on normal premature and full-term infants. J. Clin. Invest., 1955, 34, 975.

8. Howard, P. J., and Bauer, A. R., Irregularities of breathing in the newborn period. Am. J. Dis. Child., 1949, 77, 592.

9. Howard, P. J., and Bauer, A. R., Quantitative variations in the respiration of the newborn infant. Am. J. Dis. Child., 1953, 86, 284.

10. Standardization of definitions and symbols in respiratory physiology. Federation Proc., 1950, 9, 602.

11. Riley, R. L., and Cournand, A., Analysis of factors affecting partial pressures of oxygen and carbon dioxide in gas and blood of lungs: Theory. J. Applied Physiol., 1951, 4, 77.

12. Riley, R. L., Cournand, A., and Donald, K. W., Analysis of factors affecting partial pressures of oxygen and carbon dioxide in gas and blood of lungs: Methods. J. Applied Physiol., 1951, 4, 102.

13. Filley, G. F., MacIntosh, D. J., and Wright, G. W., Carbon monoxide uptake and pulmonary diffusing capacity in normal subjects at rest and during exercise. J. Clin. Invest., 1954, 33, 530.

14. Pace, N., Consolazio, W. V., White, W. A., Jr., and Behnke, A. R., Formulation of the principal factors affecting the rate of uptake of carbon monoxide by man. Am. J. Physiol., 1946, 147, 352.

15. Forbes, W. H., Sargent, F., and Roughton, F. J. W., The rate of carbon monoxide uptake by normal men. Am. J. Physiol., 1945, 143, 594.

16. Donald, K. W., and Christie, R. V., A new method of clinical spirometry. Clin. Sc., 1949, 8, 21.

17. Gaensler, E. A., and Cugell, D. W., Bronchospirometry. IV. Ambient-air and oxygen-recording bronchospirometry. J. Lab. \& Clin. Med., 1952, 40, 410.

18. Van Slyke, D., and Sendroy, J., Jr., Studies of gas and electrolyte equilibra in blood. XV. Line charts for graphic calculations by the HendersonHasselbalch equation, and for calculating plasma carbon dioxide content from whole blood content. J. Biol. Chem., 1928, 79, 781.

19. Karlberg, P., Stahlman, M. T., and Lind, J., Unpublished data.

20. Henderson, Y., and Haggard, H. W., The circulation and its measurement. Am. J. Physiol., 1925, 73, 193.

21. Eldridge, F. L., and Hultgren, H. N., The physiologic closure of the ductus arteriosus in the newborn infant. J. Clin. Invest., 1955, 34, 987. 